\title{
PANDEMIA E CRISE DA REPRODUÇÃO SOCIAL CAPITALISTA: Entrevista com a Professora Ana Carolina Gonçalves Leite
}

\author{
PANDEMIC AND CRISIS OF CAPITALIST SOCIAL REPRODUCTION: \\ Interview with Professor Ana Carolina Gonçalves Leite
}

Lucas Vinícius de Oliveira NASCIMENTOํㅗㄹ Dandara SANTANA²

Palavras-chave: Covid-19; Modernização e epidemias; Relações sociais capitalistas; Crise.

\section{RESUMO}

Entrevista realizada pelos estudantes Dandara Santana e Lucas Vinícius de Oliveira com a Profa. Dra. Ana Carolina Gonçalves Leite, todos do DCG/UFPE, sobre Covid-19 e crise da reprodução social capitalista. Os estudos críticos e interdisciplinares da professora permitiramna oferecer uma visão sobre a pandemia em curso, destacando seus nexos com a crise que já vínhamos enfrentando e cuja abrangência envolve a totalidade das relações forjadas historicamente com o desenvolvimento do capitalismo, agravando-as e ao seu potencial destrutivo da sociedade e da natureza.

\section{ABSTRACT}

Interview conducted by students Dandara Santana and Lucas Vinícius de Oliveira with Prof. Dr. Ana Carolina Gonçalves Leite, all from DCG/UFPE, about Covid-19 and crisis of capitalist social reproduction. Her critical and interdisciplinary studies have allowed her to offer an insight into the ongoing pandemic from its links with the crisis we have already been facing and whose scope involves the totality of relationships historically forged with the development of modern society, aggravating them and their destructive potential for society and nature.

\footnotetext{
${ }^{1}$ Graduando em Geografia na modalidade Licenciatura, pela Universidade Federal de Pernambuco. Atualmente é integrante do Programa de Residência Pedagógica na condição de bolsista e voluntário do Grupo de Pesquisa Movimentos Sociais e Espaço Urbano - MSEU (UFPE). E-mail: lucas.onascimento@ufpe.br

2 Graduanda em Geografia na modalidade Licenciatura, pela Universidade Federal de Pernambuco. Membro efetivo do Programa de Educação Tutorial MEC/SESu - Grupo PET Conexões Gestão Política-Pedagógica. Bolsista no Programa Institucional de Bolsas de Iniciação Científica (PIBIC) na Fundação Joaquim Nabuco (FUNDAJ). E-mail: dandarastn.ds@gmail.com
} 


\section{PREÂMBULO}

A entrevista que publicamos agora foi realizada por iniciativa dos estudantes do Departamento de Ciências Geográficas da Universidade Federal de Pernambuco (DCG/UFPE) Dandara Santana e Lucas Vinícius de Oliveira. Eles fazem parte do Grupo PET Conexões Gestão Política-Pedagógica (PET CNX GPP/UFPE), coordenado pela Profa. Dra. Vanice Selva (DCG/UFPE) e propuseram-na como base para a criação do primeiro episódio do então recém-lançado Podcast Diálogos \& Saberes. Como já viviamos a pandemia por Covid-19 que ainda hoje acomete o Brasil e o mundo, a entrevista foi realizada de maneira virtual, no dia 07 de maio de 2020. Depois de feito o convite à Profa. Dra. Ana Carolina Gonçalves Leite (DCG/UFPE), os estudantes enviaram-Ihe um conjunto de questões cujas respostas ela pôde elaborar por escrito, antes de responder a eles em chamada gravada, formulando substancial parte do texto que agora apresentamos. Além das repostas, pré-textos e preâmbulo também foram redigidos pela entrevistada enquanto introdução e perguntas foram de responsabilidade dos entrevistadores. 0 material que se tinha inicialmente foi revisado e apenas brevemente modificado, para publicação.

Dandara Santana e Lucas Vinícius de Oliveira cursam licenciatura em Geografia no DCG/UFPE. Ela pesquisa "Produção Científica no Parna Catimbau: limites e possibilidades educomunicativas" na Fundação Joaquim Nabuco (FUNDAJ) e ele "A destruição da natureza em Gravatá: sua transformação de bem comum à mercadoria", vinculado voluntariamente ao Programa de Iniciação Científica da UFPE. Ana Carolina Gonçalves Leite é professora do DCG/UFPE desde 2019. Antes disso, já havia lecionado tanto no Departamento de Geografia como no Programa de Pós-graduação em Geografia da Universidade Federal do Espírito Santo (DG e PPGG/UFES), em Vitória, no Espírito Santo. Bacharel em Ciências Sociais, desde a graduação realiza pesquisas que têm interface com a geografia, além de ter cursado mestrado e doutorado em Geografia Humana na Universidade de São Paulo (PPGH/USP). Ao longo da sua trajetória, investigou a formação e a crise do trabalho no Brasil, a partir de pesquisas sobre transformações nos processos de expropriação, de formação territorial, na mobilidade do trabalho e nas migrações, mobilizando uma leitura crítica sobre a historicidade do conceito de acumulação primitiva. Hoje vem trabalhando, em conjunto com outros pesquisadores, na elaboração de uma geografia da crise que ofereça subsídios teóricos para a análise de processos como a chamada corrida mundial por terras, os deslocamentos forçados, os padrões territoriais de confinamento - dos muros e cercas de contenção às migrações ao encarceramento em massa -, atravessados pela ficcionalização da reprodução social capitalista, sua crise e pela crise do trabalho.

\section{INTRODUÇÃO}

Como sabemos, ainda em 2019, o Covid-19, novo vírus da família Coronavírus, patógenos que causam infecções respiratórias, se manifestou pela primeira vez em dezembro, na província de Wuhan, na China, em pessoas que estavam numa feira de animais vivos. Após os primeiros casos, o vírus se propagou e 
atingiu outras pessoas daquela região, e devido ao seu fácil acesso de transmissão, o que até então era considerado uma epidemia, tornou-se uma pandemia. A urgência para adotar novas medidas de proteção, como a adoção de um grande isolamento social e fechamento de comércio e indústrias em grande escala, já estava se tornando uma obrigação, embora alguns países tenham ignorado as evidências científicas. Os desdobramentos dessa pandemia viral implicam nas crises sociais, políticas e econômicas, pelas quais 0 sistema capitalista já vem passando mundialmente em diferentes países, sobretudo na América do Sul. Além disso, revelam um impacto sobre questões ambientais e territoriais para a natureza e para populações tradicionais, como indígenas e quilombolas. Diante desse novo cenário, o mundo, a América do Sul e o Brasil lidam com diversos embates e buscam alternativas razoáveis para o combate ao Covid-19, ao mesmo tempo em que lidam com uma crise na economia e na política.

Dandara Santana/Lucas V. de Oliveira (DS/LVO): Gostaríamos de abordar a insistente comparação, por exemplo, pelos meios de comunicação, entre o Brasil e os países que estão adotando medidas menos radicais de confinamento contra o coronavírus como estratégia de legitimação do discurso de que é necessário "salvar a economia". Diante disso, o que esperar da economia brasileira no pós-pandemia?

Ana Carolina G. Leite (ACGL): Agradeço pela pergunta. Antes de respondê-la, contudo, gostaria de tecer um breve comentário sobre a introdução feita por vocês. Esse comentário vem ao caso, porque a crise em curso tem sido frequentemente tratada como uma crise provocada por um fator externo à economia, uma crise que parece ter sido causada pela pandemia. Para começar a problematizar essa ideia, nada melhor que mostrar como o surgimento e a rápida propagação do novo coronavírus são eles próprios desdobramentos por assim dizer "internos" dos circuitos do capital em sua atual fase crítica de reprodução. A visão de que a epidemia se propaga a partir dos mercados de animais vivos ou mercados úmidos de Wuhan, na China, merece assim uma reflexão mais detida. Em primeiro lugar, porque essa visão sugere, mesmo que implicitamente, uma exotização da população chinesa e do consumo de animais silvestres não raro mobilizadas para a culpabilização racista dos chineses pela pandemia, como podemos observar em comentários de líderes mundiais como Donald Trump.

Se pararmos para pensar nas últimas epidemias que abalaram o mundo, como a Síndrome Respiratória Aguda Grave (SARS), a gripe aviária ou a gripe suína, salta aos olhos, todavia, uma íntima relação entre epidemiologia e economia. Não à toa muitas dessas doenças assumiram o nome de animais produzidos em larga escala para o abate. Estudiosos como o biólogo Robert Wallace, autor do livro Big Farms Make Big Flu, recém-traduzido no Brasil como A Pandemia e o Agronegócio, e o historiador Mike Davis, que escreveu o livro Monstro Bate a Nossa Porta: A ameaça Global da Gripe Aviaria têm sugerido uma conexão entre 0 aparecimento e a disseminação desses vírus e a monopolização mundial da produção de alimentos pelo agronegócio. Nesses contextos, os vírus encontram numerosos hospedeiros da mesma espécie confinados em enormes aglomerações e condições de produção que incluem contato permanente com fezes 
e fluidos e até o aproveitamento de animais que morrem ou são descartados, depois de triturados, para a feitura de ração. Pode parecer assustador, mas esta descrição não passa das condições padrão de funcionamento de qualquer granja de produção industrial de proteína animal. Assim são removidas progressivamente quaisquer barreiras imunológicas à proliferação dos patógenos e é também ampliada a sua virulência, em função do encurtamento dos ciclos de vida em obediência às necessidades de elevada produtividade dos negócios. Vale lembrar que um frango é abatido em um tempo médio de 40 dias após sua entrada na granja.

Mas não é apenas o agronegócio já estabelecido o responsável pela gênese dessa tendência epidêmica do capitalismo tardio. Também o continuado avanço da chamada fronteira agrícola cumpre seu papel e nos permite colocar em relação gripe aviária ou gripe suína e vírus como o Ebola e o novo coronavírus, supostamente advindos dos animais silvestres. Incursões cada vez mais ostensivas a ecossistemas que não são urbanizados, não são industrializados (seja com as linhas de produção do agronegócio) vão tornando regular o contato entre aqueles animais e os seres humanos de maneira a facilitar as condições para 0 salto zoonótico desses vírus entre as espécies. Aqui jogam papel importante 0 desmatamento, a construção de estradas. Com a produção da fronteira em tais territórios, animais fogem de lá para buscar refúgio em zonas menos acessíveis e, por sua vez, também entram em contato com cepas de patógenos que se encontravam relativamente isoladas. Além disso, esses mesmos animais são incorporados nas cadeias globais de produção mercantil às vezes como alimento exótico às vezes como matéria-prima, abrindo mais uma porta para a transmissão dos vírus. Completa esse quadro a impossibilidade de isolamento entre territórios de fronteira e fazendas de confinamento já constituídas. Mesmo com medidas de contenção, a entrada de animais silvestres nessas fazendas também possibilita o salto zoonótico.

É por isso que as pestes acompanham desde sempre o processo de modernização capitalista e marcaram profundamente sua acumulação primitiva. $\mathrm{Na}$ imposição do capitalismo na Inglaterra, com 0 conhecido processo dos cercamentos, inúmeras pandemias se abateram sobre o gado que passava a ser confinado de forma inédita. E mesmo depois de contidas nas metrópoles, a ocorrência de pandemias dessa natureza persistiram por longos períodos em territórios coloniais, como no dramático exemplo da peste bovina que dizimou 80 a $90 \%$ do gado na África Subsaariana, na última década do século XIX. Além de ter contribuído para o desmantelamento de sociedades pastoris e para um ciclo de fome tremendo, aquela pandemia foi responsável ainda pela conformação de um habitat favorável a disseminação da mosca tsé-tsé e da doença do sono, implicando em limitações ao repovoamento da zona que facilitaram a dominação colonial. Analisando processos semelhantes e a interação entre crises climáticas e econômicas que originaram grandes secas, desertificação e fome, Mike Davis fala em seu livro Holocaustos Coloniais, assinalando uma mortandade comparável apenas ao holocausto nuclear. 
Assim, o novo coronavírus não é um vírus "chinês" e não tem uma dimensão supostamente cultural. Ao contrário, seu aparecimento naquele país bem como o de outros vírus se relaciona mais com os violentos processos recentes de urbanização e industrialização ocorridos na China e com sua centralidade na produção mercantil mundial hoje, posição já ocupada pela Europa ou pelos EUA em outros momentos. Em um artigo publicado na Monthly Review conjuntamente a outros parceiros, Robert Wallace menciona a confecção de mapas globais por pesquisadores financiados pela Colgate-Palmolive ou pela Johnson \& Johnson que sistematizam surtos ocorridos desde 1940 e identificam a propensão de certas áreas à ocorrência de novas epidemias. Não é por acaso que eles destacam a China, a Índia, a Indonésia e partes da América Latina e da Ásia como hotspots: se eximem da dimensão relacional da produção capitalista em prol de geografias absolutas estigmatizadoras e orientadas para externalizar as responsabilidades sobre a catástrofe da modernização seja para o sul global, para os países em desenvolvimento, com hábitos exóticos e até mesmo para a natureza, que em muitos discursos aparece como a responsável pelo surto, como se estivesse movendo uma vingança contra a humanidade.

Por isso, é necessário um adendo sobre o tratamento dualista dado sistematicamente à análise da expansão da fronteira agrícola ou da expansão capitalista. Já não existe nenhuma natureza exterior ao processo de reprodução social capitalista. A natureza não é um amontoado de recursos "externos" passíveis de serem incorporados como propriedades, matérias primas ou bens de consumo pela produção ou circulação mercantil. Ela própria vem sendo produzida historicamente com momento necessário do desenvolvimento capitalista, como afirma Neil Smith, no seu livro Desenvolvimento Desigual, relacionando a produção da natureza com a produção do espaço, essa problemática consagrada pela reflexão dos geógrafos. $O$ processo aludido engloba da produção dos novos regimes climáticos aos organismos geneticamente modificados, revelando, pois, a produção industrial da natureza de espécies e ciclos comumente pensados como naturais. A contaminação por metais pesados de terras indígenas de populações isoladas ou dos animais marinhos que habitam o fundo dos oceanos por plástico e radiação são exemplos terriveis, que evidenciam a que se presta a representação da natureza como algo "exterior" e catastrófico quando a destrutividade que vemos vem, na verdade, do próprio desenvolvimento capitalista.

A malignidade do processo, se impulsiona e completa, por fim, com a circulação dos verdadeiros barris de pólvora que são tais vírus nos circuitos globais de mercadorias. Se seu surgimento, como vimos, passa longe de qualquer caracterização acidentalista, sua disseminação em um passe de mágica se escora nos pontos de contato entre linhas regionais de suprimento de alimentos exóticos, os mercados locais inclusive aqueles de urbanização recente, entrepostos das commodities agrícolas globais - e as cadeias globais de alimentos, além da circulação tanto da força de trabalho como dos consumidores igualmente como mercadorias. Uma consideração sobre isso inverteria aquelas "geografias absolutas" dos hotspots ajudando a interpretar, por exemplo, a intensidade alcançada pela pandemia em cidades como Nova York. 
Isso tudo para começar. Deixe-me ver agora como retorno à primeira pergunta que vocês fizeram. Ela se refere ao que podemos esperar da economia no Brasil num momento posterior à pandemia. Para respondermos a essa pergunta, temos de fazer agora o exercício inverso, criticando também uma caracterização acidentalista da crise, como se a mesma tivesse sido produzida apenas pelo surto pandêmico ou fosse totalmente imprevisível, um "cisne negro", como se diz no jargão financeiro. Essa reflexão nos exige conduzir a análise para momentos anteriores ao da explosão da pandemia, para refletirmos sobre um contexto que já se achava em curso.

É verdade que o novo coronavírus e as consequências que desencadeia vem afetando numerosos mercados ao redor do mundo e que gestores de relevo como o Fundo Monetário Internacional já falam numa nova recessão da economia mundial e num choque mais profundo do que a crise de 2008 , em função da paralisação de atividades fabris, comerciais e de serviços. Ángel Gurría da Organização para Cooperação e Desenvolvimento Econômico (OCDE) afirmou em entrevista à $B B C$ que a cada mês que as grandes economias passarem em confinamento elas diminuirão em dois pontos percentuais seu crescimento anual e que um crescimento global de 1,5\% previsto para 2020 já soa otimista demais. Menos de um mês atrás, a organização havia previsto um crescimento global de $2,4 \%$, admitindo já uma queda com relação a projeção feita inicialmente em novembro, de $2,9 \%$ de crescimento.

A Conferência das Nações Unidas sobre Comércio e Desenvolvimento (UNCTAD) traduziu as consequências da pandemia em números absolutos, prevendo um custo à economia global de até US\$ 2 trilhões. 0 processo que esses números procuram representar inclui o significativo encolhimento da produção ante a paralisação das atividades, inúmeras quebras e falências, ampla deflação dos preços dos ativos nos mercados de capitais, cortes salariais profundos, demissões em massa, redução do consumo ou sua restrição a itens absolutamente imprescindíveis. Os setores sofrem de maneira diferente e uns são mais abalados que os outros, como é possível perceber comparando, por exemplo, o turismo e as companhias aéreas à indústria de EPIs ou farmacêutica. As regiões também são impactadas diferentemente, pela variedade de reações de enfrentamento da pandemia que cada Estado mobiliza e pelo momento da contaminação em que se encontra. De todo modo, mesmo quando a quarentena se restringia a alguns estados chineses seus impactos já se faziam notar na indústria automobilística ou de tecnologia europeia, que dependiam de peças e componentes importados desse país para seguir em funcionamento, o que ademais revela a preponderância que a China tem na dinâmica mundial de reprodução da industrialização. De uma maneira ou de outra, a crise se faz global, ainda que o cinismo liberal do pensamento econômico teime em apresentá-la como oportunidade, seja para o desenvolvimento do e-commerce, das cadeias logísticas e de serviços conectadas pela web ou da educação à distância. Os dados da Organização Internacional do Trabalho (OIT), por seu lado, não conseguem disfarçar o tamanho da catástrofe, sugerindo a erradicação de até 25 milhões de empregos no mundo, superando em 3 milhões a marca crítica atingida com a crise de 2008. 
Mesmo levando em conta tudo isso, a crise em curso não significou nenhum choque externo. Economistas marxistas como Michael Roberts vem argumentando que antes mesmo do seu início, a atividade econômica mundial tanto nos países em desenvolvimento como nas maiores economias do globo já sofria diminuições significativas na produção e no investimento. Mas não são só eles. Apesar do pânico gerado pelo surto epidêmico no sistema financeiro que fez os mercados de ações despencarem $30 \%$ em pouquíssimas semanas, o mundo da fantasia da escalada sem limites de ativos financiados com custos cada vez menores já apresentava sinais de esgotamento identificados até mesmo por epígonos do cassino global como 0 Financial Times. Em agosto de 2019, o jornal inglês documentava a existência de 14 bilhões de dólares em títulos com rendimentos negativos em todo o mundo. Juntava-se a essa situação uma demanda crescente por ouro, a intensificação da venda de títulos e dos limites colocados por fundos de hedge para saques, além de uma tendência de transferência de aposta da possibilidade de perder muito para a certeza de perder um pouco menos. Apresentada na linguagem cifrada dos financistas, a lista aponta a dificuldade de resolver um processo aprofundado de endividamento com mais dívidas.

O endividamento estatal e de boa parte das grandes empresas globais é tão grande que deixa de ser financiável especulativamente pela sucessão de bolhas de descomunal inflação dos preços dos ativos como foi o chamado boom das commodities. 0 quadro fica mais evidente quando comparamos o atual PIB anual mundial com a soma da dívida pública dos Estados nacionais: são cerca de 80 trilhões de dólares contra 280 trilhões de dólares, ou seja, as dívidas são 3,5 vezes maiores que o PIB. A crise que esses números mal representam é atravessada por um processo de financeirização descomunal, que, todavia, não resulta simplesmente do advento das políticas neoliberais de desregulamentação dos mercados de capitais globalizados, embora as mesmas tenham desempenhado seu papel. Esse endividamento alarmante predomina sobretudo como tentativa de superar os limites das contradições inerentes à reprodução capitalista por meio do adiantamento das expectativas de valorização futura que a dívida permite, para pagar as contas da reprodução capitalista que já quase nunca "fecham" no presente.

Essas contradições são produto da concorrência que exige dos capitais que se tornem progressivamente mais produtivos mediante seu desenvolvimento técnico, o desenvolvimento das forças produtivas apontado por Marx. Por um lado, esse desenvolvimento exige 0 adiantamento de parcelas cada vez maiores de capital - a financeirização como fenômeno tem tudo a ver com isso. Por outro, ele promove a progressiva expulsão do trabalho vivo dos processos produtivos embora o mesmo permaneça como fundamento da valorização. Como uma tendência perceptível já no século XIX, MarX apontou a queda tendencial da taxa de lucro. Pelo menos desde a terceira revolução industrial que culminou na grande crise dos anos 1970, contudo, o processo não é mais só uma tendência, mas encontrou limites absolutos em que a incorporação de novos setores, produtos e territórios de produção de valor já não compensa a perda resultante daquele desenvolvimento. Desde lá, a manutenção da reprodução capitalista depende de modo 
cada vez mais profundo de um processo de endividamento que nunca consegue chegar de fato a ser saldado, tornando-se por isso a rolagem de dívidas uma figura tão comum para representar as condições de existência das empresas, dos Estados e das famílias. Um processo já intrinsecamente destrutivo como a reprodução capitalista, que faz do mundo terra arrasada desde que seja para transformar dinheiro em mais dinheiro acaba então se tornando catastrófico pela inversão da proporção entre o valor produzido, a força de trabalho mobilizada e as matérias-primas consumidas na produção.

E mesmo com o aprofundamento da incorporação destrutiva dos chamados recursos naturais, os resultados em termos de valorização continuam ínfimos e conseguem crescer descomunalmente apenas quando passam pelas bolhas financeiras capazes de inflá-los a perder de vista, até que o próximo estouro aconteça. Por isso é que filósofos como Paulo Arantes ou Marildo Menegat vêm caracterizando a crise ambiental como um momento dessa crise fundamental capitalista e apontando a hipoteca das referidas massas de tempo futuro como o esgotamento das possibilidades de futuro das próximas gerações. Noutros termos, reafirmam a mesma queda do céu e a necessidade de adiar o fim do mundo que o pensamento indígena representado nas figuras de David Kopenawa e Ailton Krenak vem tentando alertar aos brancos.

Esse é o cenário mundial que precisamos considerar para pensar o Brasil. Para o momento posterior à pandemia, infelizmente, podemos esperar um agravamento brutal das consequências sociais dessa crise que já vinham perturbando o Brasil excepcionalmente tanto pela sua constituição racista como pela histórica desigualdade que o assola. Desemprego, intensificação das taxas de exploração do trabalho a níveis que mutilam e matam, precarização e flexibilização tendendo à uberização, aumento da viração cinicamente dissimulada como empreendedorismo, quando esses empresários das suas próprias misérias apenas tentam desesperadamente sobreviver. Além de fome, desnutrição entre outras formas de adoecimento social que vão das epidemias de inanição às de depressão. E não adianta nos restringirmos ao mundo do trabalho para analisar o quadro, porque entender a descartabilidade das pessoas diante da necessidade da reprodução do capital inclui analisar aqueles que são cotidianamente enxotados do mercado para o encarceramento massivo, o aliciamento de jovens, mulheres e outros que já não tem outras alternativas de sobrevivência para as bordas do crime organizado, e mais dramaticamente, o genocídio que cobre, hoje, de territórios periféricos negros às terras indígenas. Junto com isso, devem subir ainda mais as já grotescas taxas atuais de feminicídio, violência doméstica, alcoolismo, de mães solo responsáveis por sustentar famílias inteiras.

Não bastasse a sua perversidade fantasmagoricamente objetiva, essa descartabilidade também vai conformando uma subjetividade malthusiana que ajudou a criar o bolsonarismo. É um espírito simultaneamente suicidário e homicidário que apenas se justifica por uma espécie de adesão ao fim do mundo que abrange a terra arrasada ambiental, a necropolítica nossa de cada dia, do matar ao deixar morrer, além da representação da sociedade como uma guerra de todos contra todos em que se armar aparece como 
a única oportunidade para sobreviver. A paralela militarização e milicialização progressivas vem daí e 0 desejo patriarcal de possuir a própria arma é apenas a ponta de um iceberg.

DS/LVO: No setor trabalhista, considerando denúncias, cresce a negligência em empresas na exposição indevida de funcionários. Os setores essenciais, públicos e privados que continuam funcionando expõem o trabalhador a novas condições de trabalho, inclusive com alterações e medidas provisórias nos direitos trabalhistas. Que cenário a pandemia desenha para o trabalhador no Brasil, nesse momento de crise?

ACGL: Tenho que tentar fazer uma resposta mais enxuta que a última, para podermos terminar nossa entrevista hoje. O Brasil e o mundo do trabalho. Passa um pouco pela maneira como eu terminei a resposta à questão anterior, né? Numa entrevista que deu recentemente ao portal da UNISINOS, a jornalista Eliane Brum sugere que o Brasil vive o caos sobre o caos, com destaque para o apartheid não oficial do país. Esse é um bom começo para pensarmos sobre o problema. Ela expõe a diferenciação em curso entre aqueles que podem e os que não podem ser contaminados pelo novo coronavírus, em função da expropriação de parte significativa da população das possibilidades de se manter em isolamento físico. Por essa expropriação, respondem a emergência cotidiana da viração a que o esquadrão de trabalhadores informais, já no ano passado, quase metade daqueles que se declararam ocupados, está submetido. $\mathrm{E}$ também as práticas empresariais no estilo Madero ou Havan, admitidas orgulhosamente para os meios de comunicação em declarações estarrecedoras feitas durante à pandemia por seus representantes.

Não menos importante é a situação das trabalhadoras domésticas que seguem forçadas ao trabalho por uma classe média de perfil escravista e que vem sendo expostas pela necessidade de enfrentar 0 transporte público e, como se isso não bastasse, pela possibilidade de contrair o vírus diretamente dos seus empregadores, como no caso da primeira morte por Covid-19 ocorrida no Rio de Janeiro. E não falamos só da possibilidade de contrair o vírus, que por si já é grave, mas também da maior possibilidade de morrer a que os trabalhadores pobres estão submetidos. É só você se perguntar onde mora a empregada doméstica ou o entregador do Rappi ou do Ifood aqui em Recife e, na sequência, analisar a tabela que o Jornal do Comércio publicou dia 06 de maio de 2020. O percentual de letalidade da Covid-19 no Brejo do Beberibe é quase 7 vezes maior do que em Boa Viagem. Além de periféricos, vale dizer que esses bairros também são predominantemente negros, como são negros e negras boa parte da linha de frente dos profissionais de saúde para os quais não há possibilidade nenhuma de isolamento, sendo o esforço de não se infectar e acabar infectando toda a família aumentado ainda pela alarmante ausência de EPIs nos hospitais brasileiros. O site Alma Preta Jornalismo divulgou um estudo sobre o perfil da enfermagem feito pela Fiocruz no Brasil em 2013 que mostra que a enfermagem corresponde a 50\% dos profissionais de saúde e que dessas equipes $86 \%$ são mulheres e $53 \%$ são negros e negras.

Fazendo um pequeno desvio, é possível dizer, portanto, como o filósofo e ativista trans Paul Preciado que a imunidade não é ou se restringe a um mero fator biológico e que epidemiologia e biopolítica têm 
caminhado juntas desde o início da modernização, racializando ou estigmatizando os corpos desmunidos do horizonte de integração societário. E, como já insisti na resposta anterior, numa sociedade que produz ampliadamente descartáveis não adianta ficarmos restritos ao mundo do trabalho para compreender a profundidade do problema. Entrevistados pela Folha de São Paulo em reportagem sobre a situação enfrentada pelos moradores de rua com a pandemia, um morador do centro da cidade de São Paulo disse "Eu fui pedir ajuda para um casal. O homem berrou para eu não me aproximar da mulher porque transmito doença. Eu também o discriminei, falei que os doentes são eles". E outro: "as pessoas me olham de um jeito que parece sou o vírus". Além da fome e do descaso do poder público, denunciam a violência que marca seu tratamento como desmunidos. Assim como a imunidade, a palavra desmunido partilha a mesma raiz, "munus", que historicamente já significou o tributo necessário de ser pago para viver na comunidade.

Outra coisa importante é problematizarmos a conexão que a pergunta de vocês traz implícita entre setores essenciais e empresas que se mantiveram funcionando. Trabalhadores da Amazon, do Walmart e outras empresas de logística e comércio de variedades organizaram uma greve no dia $1^{\circ}$ de maio, nos Estados Unidos. Dentre as denúncias que incluem falta de EPIs, manutenção dos galpões em permanente funcionamento, o que inviabiliza sua desinfecção e ausência de garantias para os trabalhadores como planos de saúde, cobertura de testes e tratamentos e salário para aqueles que necessitarem fazer quarentena, destaca-se uma relacionada a questão que colocamos. Os trabalhadores apontam o pleno funcionamento também das vendas de produtos não essenciais cujo consumo virtual sofreu inclusive crescimento durante a pandemia, sendo a Amazon uma das poucas empresas que aumentou suas contratações embora também tenha dado passos na incorporação de tecnologias de dispensa de trabalho, por exemplo, inaugurando em Seattle seu primeiro supermercado sem caixas registradoras, ampliando a utilização de robôs nos seus galpões e até mesmo usando software automatizado para rastrear, quantificar a produtividade e demitir funcionários. O importante a reter é que a própria ideia de serviços essenciais soa um contrassenso confrontada a lógica capitalista de reprodução. O sentido do processo é transformar dinheiro em mais dinheiro, tanto faz se produzindo vestidos de noiva ou bombas atômicas, no capitalismo interessa apenas o resultado final, de modo que o processo de trabalho e as condições concretas de produção das mercadorias ficam abstraídas assim como as qualidades dos produtos e serviços que interessam só secundariamente, tendo alguma utilidade para haver consumo.

Vocês me perguntaram do Brasil e eu respondi com Estados Unidos. Isso também interessa pra vermos como essa situação de completa espoliação dos trabalhadores, no limite até mesmo do trabalho, não é uma questão exclusiva do Sul Global ou dos chamados países em desenvolvimento. 0 crítico alemão Robert Kurz costumava dizer que com o colapso da possibilidade de novas modernizações, a periferia da economia global assumia posição de vanguarda. Com o aprofundamento da crise, seriam as potências que alcançariam as condições trágicas das periferias, e não o contrário. Nesse sentido, 0 apartheid destacado por 
Eliane Brum não é um problema que se restringe ao Brasil. E ele está muito vivo no mundo todo e o ódio e rechaço aos migrantes que caracterizam posições e políticas nos centros do mundo já o vinham evidenciando muito antes da pandemia começar. Por isso, Paulo Arantes fala em uma fratura brasileira do mundo e destaca o uso nos Estados Unidos da expressão brasilianização para falar de processos como a ampliação das desigualdades, da desagregação nacional e outros. Quando eu estive no México em 2017 trabalhando com pesquisadores da Benemérita Universidade de Puebla eles também falavam constantemente que se aproximava a mexicanização do Brasil, destacando o papel que as milícias e outras organizações criminosas de cunho territorial assumiriam em breve. Menos de um ano depois, em 14 de março de 2018, Marielle Franco e Anderson Gomes foram executados brutalmente em condições que vão pouco a pouco se explicitando embora pareçamos nos distanciar da punição dos mandatários de crime. A desdobrar-se da mexicanização do Brasil infelizmente ocorre de modo mais e mais grave e nós ainda o estamos assistindo.

Sobre as mudanças trabalhistas que vocês comentam, se referindo provavelmente a medidas provisórias como a 927, a 936 e a 946, vale dizer que apesar do discurso acidentalista que também envolve a elas, de que flexibilizaram regras trabalhistas somente para manter empregos nesse momento de crise, as mesmas extrapolam tendências que já organizavam a reforma trabalhista como o deslocamento das negociações coletivas para os acordos individuais entre patrões e empregados, além de uma identificação cada vez mais imediata entre remuneração e jornada que vai deslegitimando a necessidade de os pagamentos incluírem benefícios, direitos e condições mínimas aos trabalhadores para que se reproduzam. $E$ vale destacar outra vez que o enorme contingente de quase metade dos trabalhadores ocupados brasileiros já estava na informalidade antes mesmo dessa crise, sem qualquer proteção social assegurada por direitos que se tornaram mais e mais combalidos depois da aprovação das reformas trabalhista e previdenciária.

Assim, apesar do nome, essas medidas não são provisórias não apenas porque muito provavelmente permanecerão, justificadas pela crise que persistirá mesmo depois de passado o confinamento. Não são provisórias também no sentido que não há nenhum normal a que vamos voltar depois da pandemia, pois esses e outros processos de barbarização já estavam em curso. Nesse sentido, nosso desejo de voltar ao normal coincide com uma normalização da catástrofe que já estávamos vivendo - catástrofe expressa também em alarmante número de mortos. O Anuário de Segurança Pública de 2019 aponta a morte de 57 mil e 341 pessoas na categoria de mortes violentas intencionais, número que sofreu redução de 10,8\% com relação ao ano anterior, e de 6 mil 220 pessoas na categoria de mortes decorrentes de intervenções policiais, cujo aumento com relação ao ano anterior foi de 19,6\%. Desse último dado, $99 \%$ são homens, $77,9 \%$ são jovens e $75,4 \%$ são negros.

DS/LVO: A maioria dos casos de Covid-19 entre os povos indígenas das Américas até então se localizam na Amazônia. A região é afetada pelo garimpo ilegal, que nesse momento se intensificou e é somado à ameaça da pandemia. Já sendo um grupo menos assistido pelo Estado, nesse momento de 
isolamento, indígenas estão ainda mais vulneráveis. Que ações poderiam ser realizadas pelo Estado para garantia de direitos e manutenção de vida dessas populações, nesse momento de urgência?

ACGL: Olha, eu fico até em dúvida sobre como responder essa pergunta de vocês. Não há como discordar que os povos indígenas são um grupo cujos direitos foram historicamente negados pelo Estado brasileiro. Inclusive, seus direitos sociais e territoriais só foram de fato assegurados com a Constituição de 1988. Ela inverteu o paradigma anterior, do Estatuto do Índio, cuja tônica era a integração das populações indígenas à sociedade abrangente, e reconheceu que as mesmas devem ser protegidas e ter suas culturas reconhecidas como seus direitos originários a suas terras e condições para a reprodução da sua vida social. Mas é necessário dizer que isso não significa que os indígenas não venham sendo assistidos pelo processo civilizatório branco e ocidental. Aí a gente teria que discutir o significado da situação experimentada por uma pessoa assistida, teria que refletir, por exemplo, sobre o significado da liberdade assistida que se abate sobre os adolescentes considerados infratores, que é na verdade uma situação de restrição de direitos. Com essa provocação eu quero explicitar que os povos indígenas, antes mesmo do seu precário reconhecimento pelo Estado brasileiro são um grupo invadido pelo Estado brasileiro, vocês entendem? E que essa invasão, de uma maneira ou de outra, legou uma espécie de liberdade assistida aos povos indígenas.

Nós estamos falando de um processo de colonização que ainda não acabou, é o que o sociólogo Aníbal Quijano chama de colonialidade do poder e, historicamente, os movimentos negros foram um dos mais importantes responsáveis por evidenciar. O Estado brasileiro nasceu desse processo colonial, mas, ao mesmo tempo, vem dando prosseguimento a ele até os dias presentes. E não se trata de uma relação travada apenas entre os povos indígenas e os Estados nacionais. Os povos indígenas foram e seguem invadidos pelas relações sociais capitalistas, por diferentes formas concretas de manifestação da sua lógica e dos seus impactos. Isso também é o processo de colonização. Mesmo se você for lá na Cabeça do Cachorro, região no extremo noroeste do Brasil, fronteira com a Colômbia e a Venezuela, mais precisamente no Vale do Javari, onde habitam grande parte dos indígenas isolados no país, mesmo lá essa invasão se manifesta, seja nas pressões que diminuem a caça, na contaminação das águas, na invasão direta por madeireiros. E eu não precisaria mencionar nada disso, a própria ideia de que existem índios isolados sitiados pelos brancos num território que antes era dos povos indígenas é uma evidência dessa ocupação. Então, como falei mais cedo comentando a produção da natureza, é preciso pensar o capitalismo como um processo abrangente, envolvente, que conforma uma totalidade invasiva mesmo dos lugares em que a gente pensa que ela não está, que a gente pensa que são o outro dela.

Essa situação invadida em que os povos indígenas se encontram é fundamental para entender a relação entre a colonização e a propagação das epidemias. No livro $A$ queda do céu, escrito a partir de falas, narrativas e conversas do xamã yanomami Davi Kopenawa com o antropólogo marroquino Bruce Albert, 0 indígena descreve o mal encontro do seu povo com diferentes braços da colonização como a Comissão 
Brasileira Demarcadora de Limites, os missionários evangélicos, o Serviço de Proteção ao Índio, os trabalhadores que atuaram na construção da estrada Perimetral Norte, os garimpeiros, os fazendeiros. Ele descreve esse mal encontro como um processo marcado pela disseminação de epidemias que foram altamente mortíferas, de sarampo, de tosse, de varíola, de malária, uma após a outra.

A chegada da Covid-19 faz parte desse processo. E como faz em todo o mundo, essa pandemia anuncia que chegamos a limites impensáveis da catástrofe causada pela civilização. Vejam só. Essa pandemia chega ao território yanomami num momento de invasão garimpeira cujas consequências são comparáveis apenas ao genocídio que acometera aquele povo desde os anos 1970 e 1980 quando 20\% da sua população foi dizimada até que ocorresse a efetiva homologação das suas terras e a lenta retirada dos garimpeiros lá de dentro. Um processo que só aconteceu por conta de muita luta dos indígenas e da sua Comissão pró-Yanomami. Eu digo genocídio literalmente, tanto porque no final dos anos 80 mais de mil yanomami morreram no Brasil com as doenças e a violência trazidas para dentro do seu território por uma invasão de 40 mil garimpeiros como em função do Massacre de Haximu, ocorrido em 1993, quando inúmeros yanomami foram assassinados e tiveram seus corpos retalhados por garimpeiros. A condenação para 0 crime, ocorrida apenas em 1997, responsabilizou Pedro Emiliano Garcia e outros quatro acusados por genocídio, pela primeira vez na história do Brasil.

Em novembro do ano passado, indígenas yanomami e ye'kwana, reunidos no seu Fórum de Lideranças, denunciaram a nova rodada de invasões dos seus territórios pelo garimpo ilegal e as brutais consequências do processo. A carta escrita no encontro aponta um contingente de invasores que pode chegar a 20 mil garimpeiros, muita violência, além do envenenamento das pessoas, rios e peixes e do afugentamento da caça. Eles citam o diagnóstico feito pela Fiocruz numa comunidade do Rio Uraricoera que aponta a contaminação de mais de $90 \%$ dos indígenas participantes da pesquisa por mercúrio. Esse cenário veio sendo produzido nos últimos 10 anos pelo aumento do preço do ouro, pela diminuição significativa dos investimentos em fiscalização e pela desativação da Bases de proteção da FUNAI na Terra Indígena. Se a situação já andava ruim, ela só fez piorar pelo atual incentivo à mineração nas terras indígenas que o governo brasileiro faz em reiteradas ocasiões.

Nesse contexto, o primeiro yanomami, um jovem de 15 anos pertencente a uma comunidade também localizada das proximidades do Rio Uraricoera, uma área muito afetada pelo garimpo, foi infectado pela Covid-19 e foi levado à morte. Entre as principais precauções para lidar com a doença, destaca-se 0 isolamento. Mas o que significa, quais são as possibilidades de isolamento quando falamos de um território invadido por 20 mil garimpeiros? Culturalmente, os yanomami vivem em casas compartilhadas e os seus utensílios circulam entre as pessoas. Além disso, por razões óbvias, têm dificuldade de acesso a sabão e a álcool. Mas esse nem de longe é o maior problema quando toda essa invasão funciona também como vetor para o vírus, como já ocorreu com outras doenças, noutros contextos históricos. Além disso, parece que 0 
garimpo ilegal tem possibilidade de se aprofundar com o preço do ouro batendo recordes semanais em função da crise, por aparecer como porto seguro quando diferentes título e investimentos ameaçam derreter.

Esse cenário de intensa ameaça vivido não apenas por indígenas yanomami e ye'kwana é complementado pelo fato de nesse momento os órgãos públicos cujo papel é controlar agressões desse como essa também estarem em quarentena. Para Paulo César Moreira, membro da Comissão Pastoral da Terra em entrevista ao site De olho nos ruralistas, isso pode estimular que agressores aproveitem o momento para ameaçar indígenas e também quilombolas e camponeses. Casos desse tipo já vem acontecendo entre os Xavante, no Mato Grosso; na comunidade Macaúba, em Goiás, que corre o risco de ter parte de suas famílias despejadas pela mineradora Vale Fertilizantes S/A; e em Alcântara, no Maranhão, onde o risco de despejo dos quilombolas se tornou premente. Além das ameaças convencionais o agente pastoral teme que a contaminação proposital dos povos indígenas seja utilizada como uma espécie de arma biológica, para atacálos de modo a facilitar apropriação fundiária e devastação ambiental.

Como se não bastasse tudo isso, o governo federal liberou a utilização de mais 46 agrotóxicos, no início de abril, em plena pandemia; a MP da grilagem continua em tramitação e seu relator disse recentemente já ter permissão de Rodrigo Maia para submetê-la ao Congresso; e o INCRA simplesmente retirou de seu Sistema de Gestão Fundiária 237 áreas rurais num montante de 9 milhões de hectares de terras indígenas pendentes de homologação que agora poderão ser vendidas, loteadas, desmembradas ou invadidas, uma vez que a Instrução Normativa n9/2020 exige da FUNAl a emissão de certificados de que tais áreas invadidas não são Terras Indígenas. Com o afrouxamento das regras atuais pela MP da grilagem, por fim, essas terras inclusive poderão ser legalizadas mediante um simples cadastro autodeclaratório.

A pergunta de vocês incluía uma sugestão de quais ações poderiam ser realizadas pelo Estado para a manutenção dos direitos e garantia da vida dos indígenas no contexto da pandemia. 0 caminho que eu percorri com minha argumentação e a lista de tragédias apontadas, para terminar, mostram como os problemas colocados exigem soluções complexas. O mínimo a fazer seria a retirada dos invasores das terras indígenas sintetizada na exigência indígena de "Fora garimpo!", embora o conjunto da obra comentada pareça mais apontar para a facilitação dessas e outras invasões. Por fim, mas não em último lugar, nos convoco a sermos provocados pelas inúmeras iniciativas e formas de organização e de luta dos indígenas que tem possibilitado o adiamento do fim do mundo por 500 anos, de maneira que ainda é possível, mesmo "depois do fim" já produzido pelos mais variados holocaustos civilizatórios, desejarmos e imaginarmos alternativas para que deixemos de ser o povo da mercadoria, como nos analisou Davi Kopenawa.

DS/LVO: A respeito dos impactos ambientais positivos, em decorrência da diminuição na emissão de gases poluentes e do ritmo desacelerado de atividades humanas que provocam degradação ambiental, como isso pode influenciar no comportamento social pós-pandemia? 
ACGL: Essa pergunta tem que ser pensada com cuidado, pois ela pode dar a entender que humanidade vem devastando o planeta e que a paralização das nossas atividades diminuiria 0 dano ambiental, preservando ecossistemas e a biodiversidade. Nomes importantes como do naturalista britânico David Attenborough chegam a comparar a influência humana na terra à ação de uma praga. Esses argumentos flertam perigosamente, contudo, com aquela subjetividade malthusiana que apontei mais cedo. Acusam os homens de se proliferarem muito rapidamente e relacionam o crescimento populacional e a devastação ambiental, sugerindo que a utilização desenfreada dos recursos finitos da terra tem fundamento demográfico. É como se dissessem que há gente demais no planeta para seus recursos limitados.

Essa leitura tem dois problemas centrais, que devem ser pensados em conjunto. 0 primeiro é que todo argumento que diz que tem gente "demais" de alguma forma corrobora com a desaparição de uma parte dessa população. E não é mera coincidência que essa desaparição venha sendo historicamente praticada como desaparecimento de parcelas racializadas e estigmatizadas, inclusas aqui todas as experiências históricas genocidas daqueles que não coincidem com a referência supostamente neutra do homem branco heterossexual ocidental. 0 segundo é que tal leitura não considera que o processo descontrolado de destruição do mundo não é próprio da humanidade, mas sim das relações capitalistas que a sujeitam, relações que são históricas. Essas relações que vêm fazendo o que for necessário para transformar dinheiro em mais dinheiro, criando o império de uma violência tanto concreta como abstrata, são também elas que dizem, do seu ponto de vista, que uma parte da população é prescindível ou torna-se progressivamente descartável. O fundamento patriarcal e racista para marcar essas populações, por sua vez, não tem nada de externos ao desenvolvimento capitalista, ao contrário, o constituem desde o seu nascimento com 0 escravismo colonial, a caça às bruxas, o confinamento doméstico da mulher.

Isso exige, por exemplo, que nos afastemos de um pensamento imediatista que culpabiliza os garimpeiros invasores dos territórios indígenas pela catástrofe em curso. Antes deles importa refletir sobre 0 garimpo - e sobre o entrelaçamento que estabelece com a produção global de mercadorias e seu caráter de piloto automático, Marx chamou de sujeito automático, acelerando com 0 abismo a sua frente. Os garimpeiros, como numerosos outros trabalhadores dos circuitos mercantis ilegais não deixam de ter sido empurrados para as margens do mundo do trabalho regulamentar e são sujeitados a condições muito precárias e relações muito violentas nas quais perderão a saúde e possivelmente a vida, muito prematuramente. Assim como os chamados pequenos vapores e aviões do tráfico, não podem ser tomados como expressão absoluta do mal, importando definitivamente observar a forma social que nos assujeita a todos ainda que de maneiras diferentes e desiguais.

A crítica dessa dominação mais geral não nos exime, contudo, de investigar condições concretas da sua reprodução. Ao contrário, convida-nos a compreender as particularidades das suas mediações, que nos possibilitarão dar a volta completa no parafuso pra pensar como aquela dominação se transforma, entra em 
crise, se acirra. Considerando ainda o exemplo do garimpo ilegal nas terras yanomami o que mais interessa é explicar como é que mesmo sem a existência de nenhum garimpo legal em Roraima nos 3 últimos anos foram exportados $771 \mathrm{~kg}$ de ouro e porque as vendas dobraram no final de 2019 para países como Índia e Emirados Árabes. Além de conectar empresas de aviação que abastecem os garimpos, laranjas que esquentam as notas como sucata de joias, tradings localizadas em Caieiras ou na Avenida Paulista cujo ritmo de funcionamento acompanha a cotação do dólar e sua alta nos momentos em que a crise se evidencia.

Para além dessa reflexão ampla sobre os efeitos ambientais da pandemia, na qual não podermos esquecer que ela própria é resultado da devastação global capitalista, é necessário considerar ainda se essa sensação de respirar melhor em função das máquinas paradas não é uma generalização construída midiaticamente explorando sobretudo a experiência urbana e da classe média. Até porque, dependendo de onde você estiver confinado, não haverá passarinhos na sua janela. Apesar disso, a sensação de alívio não é de todo falsa e denuncia o insuportável dos níveis de concorrência e produtividade que vínhamos experimentando. Para darmos somente um exemplo, já existem previsões de que a pandemia vai permitir uma aceleração do desmatamento na Amazônia. Dados do Instituto Nacional de Pesquisas Espaciais revelam um aumento de $51 \%$ com relação ao ano anterior, nível mais alto para esse período do ano desde 0 início da série, em 2016. O conjunto de fatores responsável pela elevação inclui diminuição da fiscalização com o direcionamento dos gastos públicos para a pandemia, da pressão internacional e até mesmo da atuação do exército. A pandemia desvia o foco e se multiplicam as ações criminosas e destrutivas.

Por fim, é preciso considerar que essa pandemia apenas parou a economia (e parcialmente) como resultado das suas próprias contradições, ou seja, não significou nenhuma força colocando limites ou dando um basta ao potencial destrutivo da reprodução do capital. Isso sugere que com o arrefecimento da pandemia voltemos ao inaceitável normal já bárbaro antes dela, com acréscimos produzidos por diversos mecanismos de controle social e populacional que já tem mostrado os dentes e pela pressão de que, afinal, uma hora ou outra, como dizem as más línguas, é preciso salvar a economia.

Trata-se agora de inverter essa formulação com uma pergunta que tem se tornado cada dia mais urgente. Mas cuja urgência não podemos deixar que embote uma crítica radical à catástrofe capitalista: como é que vamos nos salvar da economia? 